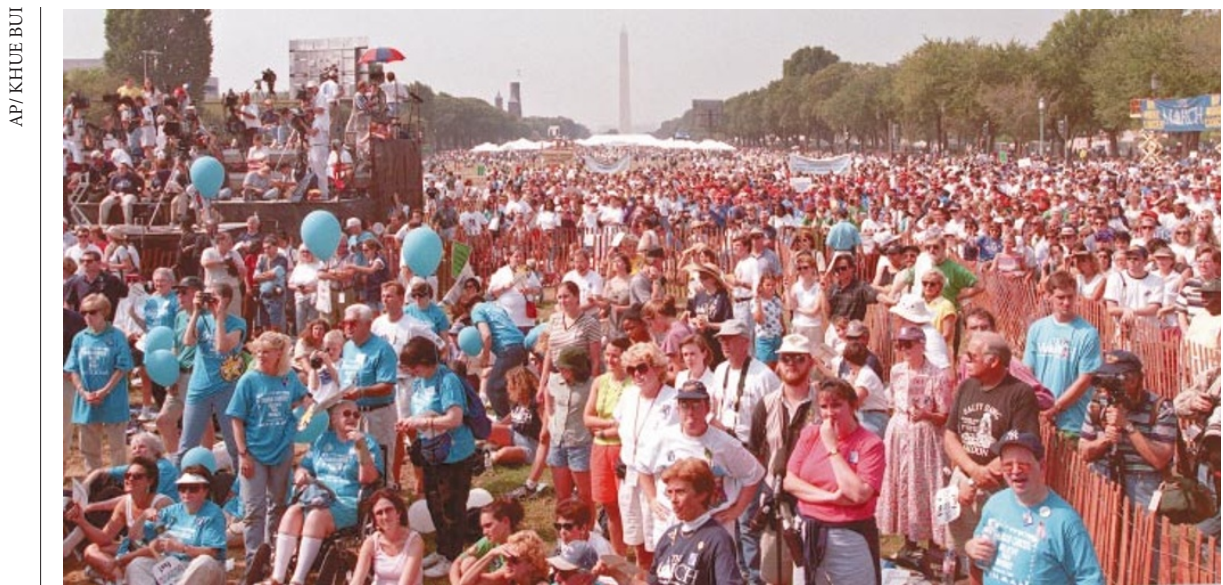

Rallying call: Washington's first annual cancer march last month demanded more cancer research.

\section{US cancer body calls for ideas from all disciplines}

[WASHINGTON] Scientists who may never have thought about applying their ideas to health research are being asked by the US National Cancer Institute (NCI) to come up with innovative technologies to support cancer research and treatment.

Under a programme to start early in the new year, NCI plans to spend $\$ 48$ million over five years on the 'unconventional innovations'. It hopes, for example, to find novel approaches for identifying molecular alterations in the body from a distance, potentially opening up an era of early and non-invasive cancer detection and treatment.

NCI has advertised the programme in Chemical and Engineering News and Physics Today, seeking ideas for solving cancer research problems from chemists, engineers, physicists and materials scientists who have had no association with health research.

The programme is part of a wider trend at the National Institutes of Health (NIH) that is likely to accelerate as it spends the $\$ 2$ billion budget windfall it received from Congress and President Bill Clinton last week (see page 734 ).

NIH institutes - of which NCI is the largest - are exploring several avenues for engaging non-biologists more fully in research to improve public health.

"We're being very open-minded right now" says Carol Dahl, director of NCI's office of technology and industrial relations, which is administering it. "We want to get people to think about the problem. We don't yet have a complete conception of all the technologies that could contribute."

The initial call for ideas, which is open until the end of November, will help Dahl's office to frame a request for contracts which will be issued early in 1999 .

The programme will look for imaging technology that could enable physicians to detect cancer in patients at a very early stage.
Genomic research at NCI is expected to identify molecular signatures for cancer. Then, imaging technology that could find such signatures in the body might allow the disease to be diagnosed long before it develops into visible tumours.

Achieving this "will require the development and integration of a series of capabilities including highly specific molecular recognition, signalling capability, controllable intervention capabilities, methods for monitoring intervention release and impact, and biotolerance," says NCI's announcement of the programme, posted on the Web (http://amb.nci.nih.gov/uip.htm).

Dahl anticipates supporting multi-disciplinary teams, bringing university scientists together with industrial partners that would be ready to commercialize the results. She plans to break with standard practice at NIH by issuing contracts rather than grants, so the researchers' work will be coordinated by staff at NCI and directed towards the goal of developing working technologies.

"By having contracts, we'll have more contact with researchers, as we try to bring together a community of scientists to work in this area," she explains.

In using contracts and imploring researchers to think "outside the box" of their own sub-discipline, the initiative appears to borrow the approach to supporting research taken by the Defense Advanced Research Projects Agency (DARPA).

DARPA used to operate chiefly in physics, engineering and computer science, but has recently extended into biology. Its approach has been praised for its results, but criticized by some scientists as over-prescriptive. Dahl says NCI looked at both DARPA and the Advanced Technology Programme at the National Institute of Science and Technology, and "attempted to extract the best aspects" ofboth.

ColinMacilwain
Proposed restrictions relaxed on research on mentally disabled

[WASHINGTON] The National Bioethics Advisory Commission (NBAC) is this week expected to endorse a final report on the protection of mentally disabled research subjects. The report is likely to be slightly less restrictive than a draft version circulated in July that was roundly criticized by US medical schools.

The report is part of a process that is likely to lead to new rules and restrictions on the use of such subjects in clinical research. But representatives of the medical schools have argued that it could inhibit vital research into Alzheimer's disease and other ailments (see Nature 394, 713; 1998).

According to Eric Meslin, executive director of NBAC, the final report will probably "broaden the discretion" of the Institutional Review Boards to permit experiments that involve some risk to patients but will not benefit them directly.

It will allow review boards to ask for a waiver from the Department of Health and Human Services to allow such research to proceed. Previous proposals to tighten control on research involving mental patients have been successfully resisted by researchers.

Meslin also says the commission will acknowledge that other groups of individuals whose ability to give informed consent is impaired, and not just the mentally ill, could be subject to the proposed extra protections. This would defuse the argument that the rules would single out psychiatric research for special scrutiny.

The final report, says Meslin, is likely to ease the requirement, proposed in the draft, that researchers carry out a "capacity assessment" of research subjects before proceeding with an experiment. The requirement will now apply only if the experiment posed more than minimal risk for the subjects, he adds.

Meslin anticipates continued resistance from researchers to the commission's recommendations. "Some of them will be acceptable and some of them will be difficult to accept," he says.

The NBAC report will be formally submitted to the National Science and Technology Council, a body made up of the government's top science administrators, which will decide what to do to implement it. "We'll also encourage voluntary compliance by researchers and Institutional Review Boards," says Meslin.

NBAC was established by President Bill Clinton in 1995 in response to several scandals concerning the treatment of human research subjects. The general performance of the review boards will be the subject of a second report from the Commission, due to be published in May 1999.

Colin Macilwain 